\title{
A comparative study of the effects of genistein and 2-methoxyestradiol on the proteolytic balance and tumour cell proliferation
}

\author{
I Fajardo, AR Quesada, I Núñez de Castro, F Sánchez-Jiménez and MÁ Medina \\ Laboratorio de Bioquímica y Biología Molecular, Facultad de Ciencias, Universidad de Málaga, E-29071 Málaga, Spain
}

\begin{abstract}
Summary The cytotoxicity of two compounds described as anti-angiogenic, the isoflavone genistein and the oestrogen metabolite 2methoxyestradiol, has been studied in different human tumour cell lines. Since the degradation of the extracellular matrix is one of the essential steps in angiogenesis, the potential modulatory effects of both compounds on the proteolytic balance in media conditioned by different human tumour cells have been also investigated. The $\mathrm{IC}_{50}$ values for 2-methoxyestradiol were lower than those for genistein on all the cell lines tested. In all the cell lines expressing measurable amounts of active enzymes, genistein induced a shift towards antiproteolysis in both matrix metalloproteinase/tissue inhibitor of metalloproteinase and urokinase/plasminogen activator inhibitor proteolytic balances. On the other hand, 2-methoxyestradiol did not produce any clear net shift of the proteolytic balance, with the significant exception of the matrix metalloproteinase/tissue inhibitor of metalloproteinase balance in WAC-2 cells, a neuroblastoma cell line with enhanced expression of the $\mathrm{N}-$ myc oncogene.
\end{abstract}

Keywords: angiogenesis; urokinase; plasminogen activator inhibitor; matrix metalloproteinase; tissue inhibitor of matrix metalloproteinase

It is well-established that malignant tumour invasion and metastasis involve a cascade of linked sequential events (Liotta et al, 1983). In addition to the loss of cell growth control, an imbalanced regulation of motility and proteolysis appears to be required for invasion and metastasis. An essential step is the breakdown and removal of extracellular matrix (ECM), mediated by several proteases, the most important of which appear to be matrix metalloproteinases (MMP) and serine proteases (Liotta et al, 1980; Danø et al, 1985; Edmonard and Grimaud, 1990). In fact, the MMPs, $72 \mathrm{kDa}$ and $92 \mathrm{kDa}$ type IV collagenases (MMP-2 and MMP-9 respectively), and the serine proteinase, urokinase-type plasminogen activator (uPA), are mainly involved in tumour invasion and metastasis (Blasi et al, 1986). On the other hand, plasminogen activator inhibitors (PAIs) and tissue inhibitors of metalloproteinases (TIMPs) are naturally occurring protease inhibitors (Andreasen et al, 1990; Liotta et al, 1991). The activity ratios UPA/PAI, MMP9/TIMP1 and MMP2/TIMP2 are maintained at a delicate balance under physiological conditions, but a temporary shift towards proteolysis is needed during tissue remodelling and normal angiogenesis (Montesano, 1992).

An imbalance of positive and negative regulation appears to be required for tumour angiogenesis, invasion and metastasis (Liotta et al, 1991). Pathological angiogenesis induced by solid tumours and required for their progression seems to be the result of an imbalance between angiogenic factors and inhibitors

Received 13 May 1998

Revised 4 August 1998

Accepted 6 November 1998

Correspondence to: MÁ Medina
(Folkman and Shing, 1992; Folkman, 1995). It is postulated that a modulation of the protease/inhibitor or angiogenic factor/ anti-angiogenic factor ratios leading to a radical decrease of any of them (that is, a shift towards inhibition of proteolytic and/or angiogenic activities) could lead to tumour regression and/or micrometastasis dormancy (Holmgren et al, 1995). Recently, a dietary-derived tyrosine kinase inhibitor and an endogenous oestrogen metabolite, namely, genistein and 2-methoxyestradiol, have been isolated from human urine and they have been shown to inhibit angiogenesis (Schweigerer et al, 1992; Fotsis et al, 1993, 1994). Since breakdown and removal of ECM is a feature shared by both angiogenesis and tumour invasion, it seemed interesting to us to study whether these compounds, genistein and 2-methoxyestradiol, can modulate the proteolytic balances in tumour cells. It was also interesting to study the relationships between their potential modulatory capacity and their ability to inhibit tumour cell growth. The present work summarizes the data we have obtained in a comprehensive comparative study of the effects of genistein and 2-methoxyestradiol on both cell proliferation and proteolytic balance in different human tumour cell lines.

\section{MATERIAL AND METHODS}

\section{Materials}

Culture media, serum and antibiotics were from Gibco (Gent, Belgium) and BioWhittaker (USA) and Trasylol from Bayer (Leverkusen, Germany). All other reagents were molecular biology grade and supplied by Sigma (St Louis, MO, USA), Bio-Rad (Hercules, CA, USA), Merck (Darmstad, Germany) and Fluka (Buchs, Switzerland). 


\section{Cell culture}

All the cell lines mentioned below were cultured in $10 \mathrm{~cm}$ diameter cell culture plates at $37^{\circ} \mathrm{C}$ under $5 \%$ carbon dioxide, in media containing streptomycin, penicillin and amphoterycin, and supplemented with $10 \%$ fetal calf serum (with the exception of WAC2 cells). Among the cells used in the present work, there were human breast cancer (MCF-7, MDA-MB231, ZR-75-1, BT-474, Hs578T and SKBR-3), neuroblastoma (LAN-5 and WAC2), colon adenocarcinoma (HT-29), fibrosarcoma (HT-1080), osteosarcoma (U2-OS) and rhabdomyosarcoma (A-204) cell lines. WAC2 cells are stable transfected neuroblastoma cells derived from the SH-EP line and containing a plasmid with the coding sequence for the N-myc oncogene (Schweigerer et al, 1990); these cells were grown in RPMI-1640 medium supplemented with $10 \%$ calf serum and selected by the addition of geneticin $\left(200 \mu \mathrm{g} \mathrm{ml}^{-1}\right)$ to the culture medium. BT-474, MDA-MB231, SKBR-3, ZR-75-1 and LAN-5 cells were grown in RPMI-1640 medium; A-204, HT-1080 and Hs578T cells were grown in Dulbecco's modified Eagle medium (DMEM) (with the addition of insulin, $10 \mu \mathrm{g} \mathrm{ml}^{-1}$, in the case of Hs578T cells); MCF-7 and HT-29 cells were grown in DMEM-F12 medium; and U2-OS were grown in McCoy's 5a medium. Cell counts were carried out with a Coulter counter.

\section{Conditioned media}

To prepare conditioned media, cells were grown in 6-well plates. When the cells were subconfluent, medium was aspirated, cells were washed twice with phosphate-buffered saline (PBS) and each well received $1 \mathrm{ml}$ of culture medium without serum and with $200 \mathrm{KIU}$ of Trasylol $\mathrm{ml}^{-1}$. Additionally, some wells received genistein $(50 \mu \mathrm{M})$ or 2 -methoxyestradiol $(10 \mu \mathrm{M})$. After $24 \mathrm{~h}$ of incubation, conditioned media were collected and centrifuged at $1000 \mathrm{~g}$ for $20 \mathrm{~min}$. Afterwards, the supernatants were collected and used for zymography. The cells were washed twice with PBS and photographed under phase contrast in a Nikon Diaphot-TMD microscope. Duplicates were used to determine cell number.

\section{Assays of toxicity}

To determine the $\mathrm{IC}_{50}$ values of the agents tested, the 3-(4,5dimethylthiazol-2-yl)-2,5-diphenyltetrazolium bromide (MTT) dye reduction assay was carried out as previously described (Mossmann, 1983).

\section{Zymographies for PA and PAI activities}

Aliquots of conditioned media normalized for equal cell numbers were subjected to sodium dodecyl sulphate-polyacrylamide gel electrophoresis (SDS-PAGE) at $4{ }^{\circ} \mathrm{C}$ under non-reducing conditions, with $3 \%$ stacking gel and $10 \%$ resolving gel. Gels were washed for 10 min twice with $2.5 \%$ Triton X-100 and twice with PBS and layed over a substrate gel prepared with agar $(0.8 \%)$, plasminogen $\left(40 \mu \mathrm{g} \mathrm{ml}^{-1}\right)$ and skimmed milk (1.5\% in PBS). Gels were incubated under a moist atmosphere overnight at $4^{\circ} \mathrm{C}$ and afterwards they were incubated at $37^{\circ} \mathrm{C}$. After $4-8 \mathrm{~h}$, bands of proteolysis due to uPA activity were photographed under dark field. After an additional day of incubation at room temperature, the only white areas under dark field illumination (due to the presence of skimmed milk protein) were those corresponding to bands protected against proteolytic activity, and they represent the bands of PAI activity.

\section{Direct and reverse gelatinolytic assays}

The gelatinolytic activity of MMP-2 and MMP-9 delivered to the conditioned media by the different tumour cells was detected in gelatinograms as follows. Samples were subjected to non-reducing SDS-PAGE as above but with gelatin $\left(1 \mathrm{mg} \mathrm{ml}^{-1}\right)$ added to the $10 \%$ resolving gel. After electrophoresis, gels were washed twice with $50 \mathrm{~mm}$ Tris- $\mathrm{HCl}, \mathrm{pH} 7.4$, supplemented with $2 \%$ Triton $\mathrm{X}-100$, and twice with $50 \mathrm{~mm}$ Tris-HCl, $\mathrm{pH}$ 7.4. Each wash was for $10 \mathrm{~min}$ and with continuous shaking. After the washes, the gels were incubated at $37^{\circ} \mathrm{C}$ for $24 \mathrm{~h}$ immersed in a substrate buffer (50 mM Tris- $\mathrm{HCl}, \mathrm{pH} 7.4$, supplemented with $1 \%$ Triton $\mathrm{X}-100$, $5 \mathrm{~mm}$ calcium chloride and $0.02 \% \mathrm{Na}_{3} \mathrm{~N}$ ). Afterwards, the gels were stained with Commassie blue R-250 and the bands of gelatinase activity could be detected as non-stained bands in a dark, stained background. To detect stromelysin, caseinograms were carried out as described for gelatinograms, using $\alpha$ - or $\beta$-casein at $1 \mathrm{mg} \mathrm{ml}^{-1}$ instead of gelatin.

To detect TIMP activities some modifications were required. Media conditioned by PMA-treated HT-1080 cells were treated with $2 \% \mathrm{SDS}$ at room temperature for $30 \mathrm{~min}$ and added $(20 \% \mathrm{v} / \mathrm{v})$ to the $12 \%$ resolving gel. Prior to the addition of the stacking gel, an electrophoretic run was carried out until the moment in which the front line containing the phenol red of the conditioned medium reached the end of the gel. From here on the procedure was the same as in the case of direct gelatinolytic assay. In this case, the bands of TIMP activity could be detected as dark bands over a clearer background.

\section{Quantitative analysis of bands of activity}

Bands of activity in the zymograms and gelatinograms were quantified with an lbas image analyser.

\section{RESULTS}

\section{Effects of genistein and 2-methoxyestradiol on tumour cell proliferation}

The effects of both compounds, genistein and 2-methoxyestradiol, have been tested on a wide range of human tumour cell lines, including breast cancer (BT-474, Hs578T, MCF-7, MDA-MB231, ZR-75-1), colon adenocarcinoma (HT-29), neuroblastoma (LAN-5, WAC2), osteosarcoma (U2-OS), rhabdomyosarcoma (A-204) and fibrosarcoma (HT-1080) cell lines.

First of all, it was necessary to access the growth rate curves obtained for the different cell lines in the culture conditions of our lab. As expected, the profiles of all the curves were similar, though the proliferation rates varied in a wide range (Figure 1). Among breast cancer cell lines, the most proliferant one was MDAMB231, a hormone-insensitive cell line. MCF-7 cells had a medium proliferation rate, and all the other breast cancer cell lines showed the lowest proliferation rates. Both rhabdomyosarcoma A-204 and fibrosarcoma HT-1080 cells showed complete growth curves in the period tested with regression of the populations from the fourth day; their proliferation rates were medium. Osteosarcoma U2-OS cells also had a medium proliferation rate but they grew continuously from the second to the sixth day showing no sign of regression. Finally, the highest proliferation rates were those of colon adenocarcinoma HT-29 and neuroblastoma (WAC2, LAN-5) cell lines, with decay of the growth from the fourth day on, only for LAN-5 cells. 

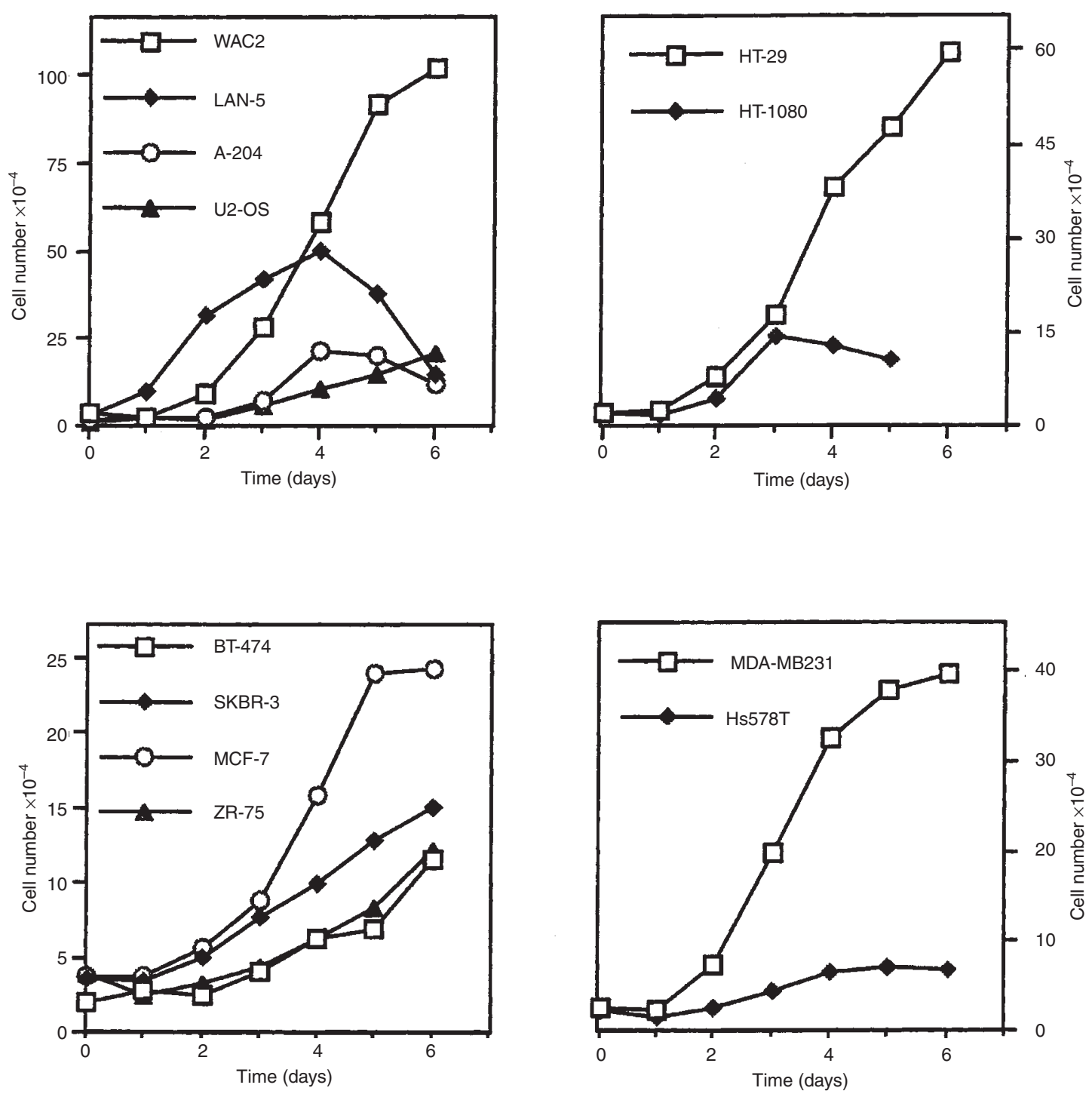

Figure 1 Growth profiles for the different human tumour cell lines tested under the culture conditions described in Material and Methods

The $\mathrm{IC}_{50}$ values for both compounds were determined by functional viability assays with MTT (Table 1). There were no clear correlations among $\mathrm{IC}_{50}$ values and the proliferation rates or the cell types. Significantly, among breast cancer cell lines, the hormone-independent MDA-MB231 cell line was much more sensitive to toxicity by both compounds than the other, hormonedependent breast cancer cell lines tested. In all the cases, $\mathrm{IC}_{50}$ values for 2-methoxyestradiol were much lower than those for genistein.

Figures 2 and 3 show the typical morphological changes induced by both treatments on some of the cell lines tested. Genistein-treated cells emitted projections, suggesting that they had acquired a differentiated phenotype. Some cells resembled apoptotic cells with blebbing of the cytoplasm. On the other hand, 2-methoxyestradiol-treated cells losed their shape and acquired a more rounded aspect.

\section{Screening of proteases and their inhibitors in media conditioned by tumour cells}

Table 2 summarizes the results of the screening of the ECM proteases and protease inhibitors delivered by the tumour cells to the culture media carried out in the present work. None of the activities which were tested could be detected in media conditioned by the low proliferation rate BT-474 and ZR-75-1 breast cancer cells. We also failed to detect any of the activities in the medium conditioned by the highly proliferant LAN-5 neuroblastoma cells. Therefore, these three cell lines could not be further used in the study of the potential modulatory effects of genistein and 2-methoxyestradiol on the proteolytic balances.

The most interesting results were obtained with the media conditioned by A-204, Hs578T, HT-1080, MDA-MB231, U2-OS and WAC2 cells, which were further analysed. Only one of the 
Table 1 Comparison of the antiproliferative effect of genistein and 2methoxyestradiol on human tumor cell lines

\begin{tabular}{lcc}
\hline & \multicolumn{2}{c}{ IC $_{50}(\mu \mathrm{M})$} \\
\cline { 2 - 3 } Tumour line & Genistein & 2-Methoxyestradiol \\
\hline BT-474 & 33 & 12.0 \\
Hs578T & 65 & 1.0 \\
MCF-7 & 72 & 3.0 \\
MDA-MB231 & 23 & 0.4 \\
SKBR-3 & 65 & 2.7 \\
ZR-75 & 128 & 31.0 \\
A-204 & 25 & 0.7 \\
HT-1080 & 100 & 1.6 \\
HT-29 & 32 & 5.5 \\
LAN-5 & 25 & 1.0 \\
U-2OS & 185 & 2.3 \\
WAC2 & 24 & 0.8 \\
& & \\
\hline
\end{tabular}

activities tested was detected in the media conditioned by HT-29 and MCF-7 (TIMP activity) and SKBR-3 cells (MMP-2 activity).

Since MMP-9 activity was only detected in HT-1080 and U2-OS cells, we restricted our study to the evaluation of the MMP-2/TIMP-2 and uPA/PAI proteolytic balances.

\section{Effects of genistein and 2-methoxyestradiol on type IV collagenase and TIMP activities}

Figure 4 summarizes the results obtained with gelatinolytic assays in both direct and reverse zymograms. As mentioned above, $92 \mathrm{kDa}$-type IV collagenase (MMP-9) was only detected in the media conditioned by HT-1080 and U2-OS cells. In reverse zymograms, two bands of TIMP activity were detected but we only further analysed the most prominent one, that corresponding to TIMP-2. Table 3 shows the normalized quantitative data obtained by digital analysis of the gelatinograms. In all the cases tested,
Table 2 Screening for the detection of ECM proteases and protease inhibitors by zymograms ${ }^{a}$

\begin{tabular}{|c|c|c|c|c|c|c|}
\hline $\begin{array}{l}\text { Tumour } \\
\text { line }\end{array}$ & MMP-9 & MMP-2 & Stromelysins & TIMPs & UPA & PAls \\
\hline BT474 & - & - & - & - & - & - \\
\hline Hs578T & - & + & - & + & - & - \\
\hline MCF-7 & - & - & - & + & - & - \\
\hline \multicolumn{7}{|l|}{ MDA- } \\
\hline MB231 & - & - & - & + & $t^{\mathrm{b}}$ & $+^{c}$ \\
\hline SKBR-3 & - & + & - & - & - & - \\
\hline ZR-75 & - & - & - & - & - & - \\
\hline A-204 & - & - & - & + & + & - \\
\hline HT-1080 & + & + & - & + & + & - \\
\hline HT-29 & - & - & - & + & - & - \\
\hline LAN-5 & - & - & - & - & - & - \\
\hline WAC2 & - & + & - & + & + & + \\
\hline U2-OS & + & + & - & + & - & + \\
\hline
\end{tabular}

aThe activities detected are indicated by + and those undetectable under the experimental conditions are indicated by - . buPA activity could only be detected in media conditioned by genistein-treated cells. CPAl activity could only be detected in media conditioned by 2 -methoxyestradiol-treated cells.

genistein induced a significant decrease in gelatinolytic activities (greater for MMP-2 activity than for MMP-9 activity). Furthermore, in HT-1080 and WAC-2 cells a parallel increase in the size of TIMP-2 activity bands was observed. Both effects accounted for an important decrease in the MMP-2/TIMP-2 proteolytic balance.

The results obtained with 2-methoxyestradiol were less conclusive. In fact, in media conditioned by Hs578T-, HT-1080- or U2-OS-treated cells, there were simultaneous increases in both gelatinolytic and TIMP activities with no significant changes in the proteolytic balance. On the contrary, in media conditioned by WAC2-treated cells, there were more pronounced increases in the TIMP activities than those produced in the gelatinolytic activities,
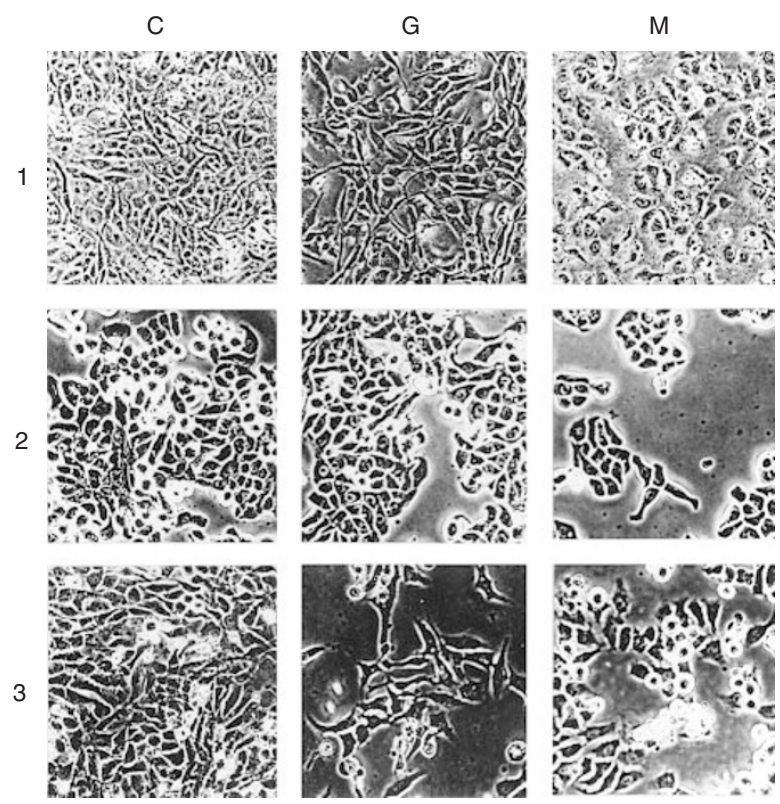

Figure 2 Effects of genistein $(G)$ and 2-methoxyestradiol $(M)$ on the morphology of cultured human tumour HT-1080 (1), HT-29 (2) and WAC2 (3) cells, as compared to control cells (C)
C
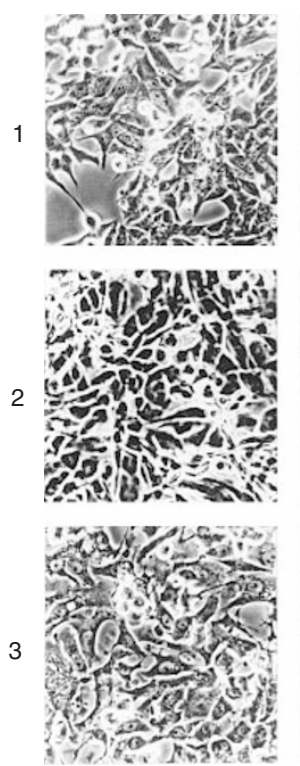
morphology of cultured human tumour MCF-7(1), MDA-MB231 (2) and SKBR-3 (3) cells, as compared to control cells (C) 
Table 3 Quantification of MMP-2 and TIMP-2 activities by image analysis

\begin{tabular}{llll}
\hline $\begin{array}{l}\text { Treatment/cell } \\
\text { line }\end{array}$ & MMP-2 activity $^{\mathrm{a}}$ & TIMP-2 activity $^{\mathrm{a}}$ & MMP-2/TIMP-2 $^{\mathrm{b}}$ \\
\hline $\begin{array}{l}\text { Genistein } \\
\text { Hs578T }\end{array}$ & $0.82 \pm 0.07^{\mathrm{c}}$ & $1.08 \pm 0.20$ & $0.78 \pm 0.11^{\mathrm{c}}$ \\
HT-1080 & $0.72 \pm 0.02^{\mathrm{c}}$ & $1.20 \pm 0.02^{\mathrm{c}}$ & $0.60 \pm 0.01^{\mathrm{c}}$ \\
U2-OS & $0.75 \pm 0.12^{\mathrm{d}}$ & $0.99 \pm 0.16$ & $0.75 \pm 0.08^{\mathrm{c}}$ \\
WAC2 & $0.77 \pm 0.01^{\mathrm{c}}$ & $1.37 \pm 0.10^{\mathrm{c}}$ & $0.54 \pm 0.00^{\mathrm{c}}$ \\
2-Methoxyestradiol & & & \\
Hs578T & $1.10 \pm 0.10$ & $1.16 \pm 0.25$ & $0.97 \pm 0.14$ \\
HT-1080 & $0.88 \pm 0.25$ & $1.26 \pm 0.24$ & $0.71 \pm 0.24^{\mathrm{d}}$ \\
U2-OS & $1.21 \pm 0.28$ & $1.17 \pm 0.17$ & $1.08 \pm 0.36$ \\
WAC2 & $1.09 \pm 0.03^{\mathrm{d}}$ & $1.36 \pm 0.04^{\mathrm{c}}$ & $0.79 \pm 0.01^{\mathrm{c}}$ \\
\hline
\end{tabular}

aResults are means \pm s.d. of three different experiments, except in the case of WAC2 cells, where they are means of two different experiments. Results are given as the ratios of activities (treated cells/control cells). Thus, a value below 1 indicates a decrease and a value over 1 indicates an increase in activity as compared to control values. ${ }^{\mathrm{b}}$ These are ratios of the values given in the two previous columns. Here, a value below 1 indicates that the treatment induced a shift towards antiproteolysis and a value over 1 indicates that the treatment induced a shift towards an increased proteolysis. 'Significant versus control values $(P<0.01)$ and dsignificant versus control values $(P<0.05)$, according to a non-parametric Mann-Whitney's $U$-test.

Table 4 Quantification of plasminogen activator and plasminogen activator inhibitor activities by image analysis ${ }^{\mathrm{a}}$

\begin{tabular}{lcc}
\hline Treatment/tumour line & uPA activity & PAl activity \\
\hline Genistein & & \\
A-204 & 0.30 & - \\
HT-1080 & 0.52 & - \\
U2-OS & - & 1.30 \\
WAC2 & 0.00 & 12.00 \\
2-Methoxyestradiol & & \\
A-204 & 1.65 & - \\
HT-1080 & 1.26 & - \\
U2-OS & - & 0.94 \\
WAC2 & 2.14 & - \\
\hline
\end{tabular}

aQuantitative data here shown are the results of image analysis of data shown in Figure 2. They are typical results and they are given as the ratios of activities (treated cells/control cells). Thus, a value below 1 indicates a decrease and a value over 1 indicates an increase in activity as compared to control values. A minus sign indicates that there was no detectable activity in control cells under the experimental conditions.

giving rise to a significant decrease of the proteolytic balance (Table 3). In media conditioned by 2 -methoxyestradiol-treated SKBR-3 cells, the only activity detected, namely that corresponding to MMP-2, was apparently increased by $25 \%$ as compared to control, untreated cells (results not shown).

\section{Effects of genistein and 2-methoxyestradiol on uPA and PAl activities}

Figure 5 shows typical results obtained in the zymograms carried out to detect PA and PAI activities, and Table 4 shows the normalized quantitative data obtained by digital analysis of the zymograms. As it was the case for the MMP-2/TIMP-2 balance, genistein strongly modified the UPA/PAI balance to antiproteolysis in WAC2 cell conditioned media by simultaneous increase of PAI and decrease of uPA activities. It is noteworthy to remark the

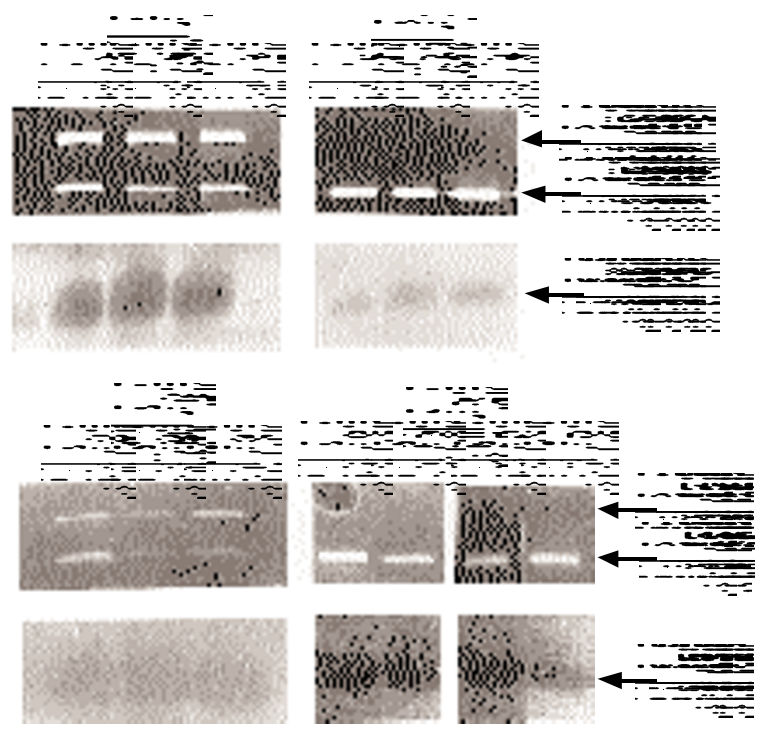

Figure 4 Bands of gelatinolytic activities (MMP-9 and MMP-2) or TIMP-2 activity detected by direct or reverse gelatinograms, respectively, of media conditioned by human tumour HT-1080 (A), Hs578T (B), U2-OS (C), or WAC-2 (D). Treatments: control, untreated cells (C), $50 \mu \mathrm{M}$ genistein (G), or $10 \mu \mathrm{M}$ 2-methoxyestradiol (M)

A

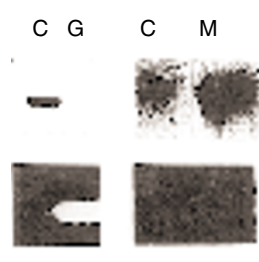

C

\section{C $\quad G \quad M$}

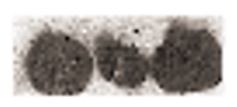

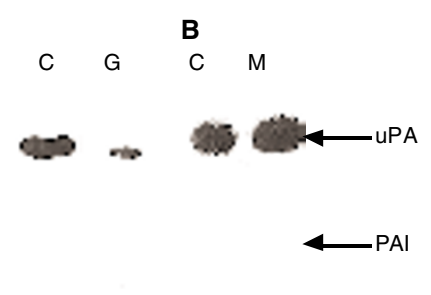

D

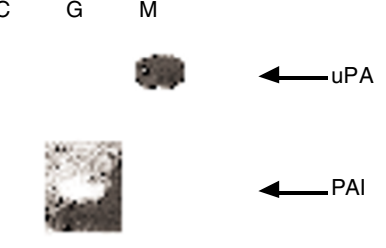

E

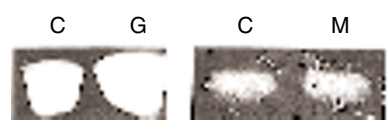

Figure 5 Bands of uPA or PAl activities detected by plasminogen zymography of media conditioned by human tumour WAC2 (A), A-204 (B), HT-1080 (C), MDA-MB231 (D) or U2-OS (E). Treatments: control, untreated cells $(\mathrm{C}), 50 \mu \mathrm{M}$ genistein $(\mathrm{G})$, or $10 \mu \mathrm{M}$ 2-methoxyestradiol (M).

dramatic increase in PAI activity detected in the medium conditioned by genistein-treated WAC2 cells as compared to untreated cells. In all the cases, genistein produced a pronounced decrease in uPA and an increase in PAI activity.

On the other hand, 2-methoxyestradiol increased uPA activity in A-204, HT-1080 and WAC2 cell conditioned media and it produced no significant effect on the PAI activity detected in U2-OS conditioned media. 
The case of MDA-MB231 cells is interesting: media conditioned by control, untreated cells contained no detectable uPA or PAI activities; however, the treatment with $50 \mu \mathrm{M}$ genistein gave rise to a detectable band of PAI activity and, on the contrary, the treatment with $10 \mu \mathrm{M}$ 2-methoxyestradiol gave rise to a detectable band of uPA activity.

\section{DISCUSSION}

\section{Modulation of tumour cell proliferation}

The interest in genistein as a potential anti-cancer agent can be traced back to the seminal work by Akiyama et al (1987) which firstly showed that it was a specific and quite potent inhibitor of protein tyrosine phosphorylation. It has been shown that genistein inhibits both oestrogen and growth factor stimulated proliferation of human breast cancer cells (Peterson and Barnes, 1996). This dual role of genistein is consistent with its previously proposed role as agonist/antagonist of oestrogen activity (Barnes et al, 1994). In fact, genistein inhibits the growth of both oestrogendependent and oestrogen-independent breast cancer cells, as firstly reported by Peterson and Barnes (1991). The interest in genistein as a potential therapeutic agent was reinforced when it was isolated from human urine and it was shown to inhibit tumour cell growth in some paediatric tumour cell lines and in some models of neoplasia in vivo (Schweigerer et al, 1992; Fotsis et al, 1993). Our results show that both compounds are inhibitory for the growth of a wide range of tumour cells. In particular, our data confirm that previously reported by Peterson and Barnes (1991), stating that genistein can inhibit the proliferation of human breast cancer cells. At the same time, the cytotoxicity of these compounds was much lower on non-neoplastic cells (results not shown). The morphological changes induced by genistein in highly proliferant tumour cells suggest that this compound could contribute to a reversion of the tumoural phenotype. Interestingly, it has been shown that genistein can induce some cancer cells to enter apoptosis (Gorczyca et al, 1993).

As was the case for genistein, 2-methoxyestradiol was also isolated from human urine and it was shown to inhibit tumour cell growth in some paediatric tumour cell lines and in some models of neoplasia in vivo (Fotsis et al, 1994). We have found that, in general, 2-methoxyestradiol was more toxic to tumour cells than genistein. On the other hand, the effect induced by 2-methoxyestradiol on cell morphology reinforces the mechanism of action suggested by Fotsis et al (1994): as 2-methoxyestradioltreated cells lose their shape, it could be speculated that this is the result of some kind of cytoskeleton disruption. In fact, it has been shown that 2-methoxyestradiol acts as a ligand for tubulin by binding to the colchicin site of this cytoskeleton protein, inhibiting the assembly of the tubulin monomer or the stability of the tubulin polymer (D'Amato et al, 1994). This interference with the microtubular net could explain the potent anti-tumour effect of 2-methoxyestradiol. Due to the similarity in the actions of both agents, taxol and 2-methoxyestradiol, it could be suggested that 2-methoxyestradiol could induce apoptosis, as taxol does, and that this induction occurs in parallel to an activation of p34cdc2 (Donaldson et al, 1994); this suggestion remains to be tested.

\section{Modulation of the proteolytic balance}

A second common point of interest of genistein and 2methoxyestradiol is their demonstrated capacity to inhibit angiogenesis (Fotsis et al, 1993, 1994), because of the fact that solid tumour progression and metastasis are dependent on angiogenesis (Folkman and Shing, 1992). An essential step in cancer invasion, angiogenesis and metastasis is a proteolytic degradation of ECM (Liotta et al, 1991). A positive correlation among tumour invasiveness and ECM protease levels has been shown (Kohn and Liotta, 1995). On the other hand, experimental evidences accumulate for a negative correlation between TIMP activities and the metastasic potential of tumour cells (Álvarez et al, 1990; Tsuchiya et al, 1993). Thus, it seems that there is a direct relationship between an imbalance of the proteolytic equilibrium towards proteolysis and the onset of tumour invasion and metastasis. In fact, Packman et al (1995) have found in thyroid follicular carcinoma that both UPA and type IV-collagenases are expressed at higher levels in a more invasive cell line (FTG-238) than in a less invasive one (FTG-133). Lau et al (1995) have found in colorectal adenocarcinoma samples higher level of uPA and its receptor than in their corresponding healthy, control samples. Stearns et al (1993) have found a positive correlation among MMP2 expression and malignancy in bladder cancer.

Two main conclusions can be derived from all these findings. First, the evaluation of the expression levels of ECM proteases and their inhibitors could have a prognostic value. In fact, it has been shown that both MMP-9/TIMP-1 and MMP-2/TIMP-2 ratios are lower in cervix carcinoma with a good prognosis than in those with a bad prognosis (Nuovo et al, 1995) and that the MMP-2/TIMP-2 ratio is high in relapsed urothelial cancers (Gohji et al, 1996). It should be stressed that the changes in the values of the protease/inhibitor ratios are more significant than the changes only in the levels of either proteases or inhibitors. Our own results shown here support this hypothesis and seem to indicate that zymograms are convenient, easy, rapid, sensitive and economic procedures to evaluate the proteolytic balance. However, the use of the proteolytic balance values as prognostic indicators requires the establishment of acceptable reference patterns as well as the determination of the cancer types where this method could be useful.

A second hypothesis is that the modulation of the proteolytic balance towards antiproteolysis could avoid tumour invasion and metastasis. In fact, this suggestion is also supported by several experimental data (Liotta et al, 1991; Montesano, 1992). Thus, the modulation of the proteolytic balance could be a promising anti-tumour strategy, and it would be noteworthy to promote the search for new compounds with a potential capacity to shift the proteolytic balance towards antiproteolysis.

Genistein has been described as a natural inhibitor of tumour cell growth (Peterson and Barnes, 1991; Schweigerer et al, 1992). Afterwards, it has been shown that genistein is an inhibitor of angiogenesis; in fact, genistein inhibits vascular endothelial cell proliferation through collagenic matrices as newly formed capilars (Fotsis et al, 1993). It was postulated that the anti-angiogenic effect of genistein could be due to its effect on ECM proteases and their inhibitors. This hypothesis was initially supported by the reported inhibitory effect of genistein on both uPA and PAI activities delivered to culture media conditioned by vascular endothelial cells (Fotsis et al, 1993). Recently, we have shown that genistein reduces the levels of MMP-2 activity in some paediatric tumour cell lines (García de Veas et al, 1995). The present report expands our previous preliminary observations to a wider range of tumours, and emphasizes the modulatory effect of genistein on the MMP2/TIMP-2 and uPA/PAI ratios towards antiproteolysis in different 
tumour cell lines; interestingly, this antiproteolytic effect is the result of both inhibition of proteases and activation of protease inhibitors.

On the other hand, since 2-methoxyestradiol has been described as an anti-angiogenic compound able to inhibit the induction of uPA activity by basic fibroblast growth factor in vascular endothelial cells (Fotsis et al, 1994), we postulated that this compound could modulate the proteolytic balance in a similar way to that proven for genistein. This was not the case, as demonstrated in the present work. Our results show that $24 \mathrm{~h}$ of treatment with $10 \mu \mathrm{M}$ 2-methoxyestradiol induces either an apparent increase of uPA activity or an apparent decrease of PAI activity. The effects of 2-methoxyestradiol on the MMP-2/TIMP-2 ratio seem to be dependent on the cell line tested. Thus, it seems that the antiangiogenic effect of 2-methoxyestradiol is not only due to a modulation of the proteolytic balance. Taking into account the effects of this compound on cell morphology caused by its capacity to bind cytoskeleton proteins, we suggest that its anti-angiogenic effect could be produced by some interferences in the first step of adhesion to the ECM previous to its degradation; interferences in the posterior step of migration cannot be ruled out.

\section{CONCLUSION}

It seems that this new strategy of searching for efficient and selective modulators of the proteolytic balance could be very promising for cancer research; furthermore, these findings would be relevant for the design and establishment of new therapeutic strategies against other diseases in which a pathological angiogenesis is involved. However, it should be kept in mind that tumour promotion, invasion and metastasis are very complex phenomena in which many gene products other than ECM proteases and their inhibitors are involved. In the present comparative study, we demonstrate that genistein is an anti-angiogenic compound able to modulate the proteolytic balance towards antiproteolysis, but the anti-angiogenic compound 2-methoxyestradiol has no clear antiproteolytic effect. Other possibilities remain to be elucidated in further experimental efforts.

In addition to the potential therapeutic value of genistein, a dietary-derived tumour cell growth inhibitor, its preventive value should be stressed. In fact, people in some Asian contries consume on the average 20-50 times more soy products (rich in genistein) than in Western countries (Messina et al, 1994), where breast, prostate and bladder cancer mortalities are higher (Dunn, 1975; Severson et al, 1989; Parker et al, 1996).

\section{ACKNOWLEDGEMENTS}

This work was partially supported by a Grant of the University of Málaga (MAM), DGICYT Grant SAF98-0150 (FSJ) and funds from PAI \#3309 from the Junta de Andalucía (INC).

\section{REFERENCES}

Akiyama T, Ishida I, Nakagawa S, Ogawara H, Watanabe S, Itoh N, Shibuya M and Fuami Y (1987) Genistein, a specific inhibitor of tyrosine-specific protein kinases. J Biol Chem 262: 5592-5595

Alvarez O, Carmichael DF and Declerk YA (1990) Inhibition of collagenolytic activity and metastasis of tumor cells by a recombinant human tissue inhibitor of metalloproteinases. J Natl Cancer Inst 82: 589-595

Andreasen PA, Georg B, Lund LR, Riccio A and Stacey SN (1990) Plasminogen activators inhibitors: hormonally regulated serpins. Mol Cell Endocrinol 68: $1-19$
Barnes S, Peterson G, Grubbs C and Setchell K (1994) Potential role of dietary isoflavones in the prevention of cancer. In Diet and Cancer: Markers, Prevention, and Treatment, Jacubs MM (ed) pp. 135-147. Plenum Press: New York

Blasi F, Riccio A and Sebatio G (1986) Human plasminogen activators: genes and protein structure. In Human Genes and Diseases, Blasi F (ed), pp. 377-414. Wiley: London

D'Amato RJ, Lin CM, Flynn E, Folkman J and Hamel E (1994) 2-Methoxyestradiol, an endogenous mammalian metabolite, inhibits tubulin polymerization by interacting at the colchicine site. Proc Natl Acad Sci USA 91: 3964-3968

Danø K, Andreasen PA, Grøhndahl-Hansen J, Kristensen P, Nielsen LS and Skriver L (1985) Plasminogen activators, tissue degradation and cancer. Adv Cancer Res 44: 139-266

Donaldson KL, Goolsby G, Kiener PA and Wahl AF (1994) Activation of p34dcd2 coincident with taxol-induced apoptosis. Cell Growth Differ 5: $1041-1050$

Dunn JE (1975) Cancer epidemiology in populations of the United States - with emphasis on Hawaii and California - and Japan. Cancer Res 35 3240-3245

Edmonard H and Grimaud JA (1990) Matrix metalloproteinases. A review. Cell Mol Biol 36: 131-153

Folkman J (1995) Angiogenesis in cancer, vascular, rheumatoid and other disease. Nature Med 1: 27-31

Folkman J and Shing Y (1992) Angiogenesis. J Biol Chem 267: 10931-10934

Fotsis T, Pepper M, Adlercreutz H, Fleischman G, Hase T, Montesano R and Schweigerer L (1993) Genistein, a dietary-derived inhibitor of in vitro angiogenesis. Proc Natl Acad Sci USA 90: 2690-2694

Fotsis T, Zhang Y, Pepper MS, Adlercreutz H, Montesano R, Nauroth PP and Schweigerer L (1994) The endogenous oestrogen metabolite 2methoxyoestradiol inhibits angiogenesis and suppresses tumour growth. Nature 368: $237-239$

García de Veas R, Schweigerer L and Medina MA (1995) Matrix metalloproteinase2 and tissue inhibitor of metalloproteinase- 2 expression in paediatric tumor cells. Effects of tumor cell proliferation modulators on gelatinolytic activity. J Cancer Res Clin Oncol 121: 275-278

Gohji K, Fujimoto N, Fujii A, Komiyama T, Okawa J and Nakajima M (1996) Prognostic significance of circulating matrix metalloproteinase- 2 to tissue inhibitor of metalloproteinases-2 ratio in recurrence of urothelial cancer after complete resection. Cancer Res 56: 3196-3198

Gorczyca W, Gong J, Ardelt B, Traganos F and Darzynkiewicz Z (1993) The cell cycle related differences in susceptibility of HL-60 cells to apoptosis induced by various antitumor agents. Cancer Res 53: 3186-3192

Holmgren L, O'Reilly MS and Folkman J (1995) Dormancy of micrometastases: balanced proliferation and apoptosis in the presence of angiogenesis suppression. Nature Med 1: 149-153

Kohn EC and Liotta LA (1995) Molecular insights into cancer invasion: strategies for prevention and intervention. Cancer Res 55: 1856-1862

Lau HKF, Kim M, Koo J, Chiu B and Murray D (1995) Increase of a urokinase receptor-related low-molecular-weight molecule in colorectal adenocarcinomas. Clin Exp Metastasis 13: 492-498

Liotta LA, Tryggvason K, Garbisa S, Hart IR, Foltz CM and Shaflie S (1980) Metastatic potential correlates with enzymatic degradation of basement matrix collagen. Nature 284: 67-69

Liotta L, Rao CN and Bardsky SH (1983) Tumor invasion and the extracellular matrix. Lab Invest 49: 639-649

Liotta LA, Steeg PS and Stetler-Stevenson WG (1991) Cancer metastasis and angiogenesis: an imbalance of positive and negative regulation. Cell 64: $327-336$

Messina MJ, Persky V, Setchell KDR and Barnes S (1994) Soy intake and cance risk: a review of the in vitro and in vivo data. Nutr Cancer 21: 113-131

Montesano R (1992) Regulation of angiogenesis in vitro. Eur J Clin Invest 22 504-515

Mossmann T (1983) Rapid colorimetric assay for cellular growth and survival: application to proliferation and cytotoxicity assays. J Immunol Method $\mathbf{6 5}$ : $55-63$

Nuovo GJ, MacConnell PB, Simsir A, Valea F and French DL (1995) Correlation of the in situ detection of polymerase chain reaction-amplified metalloproteinase complementary DNAs and their inhibitors with prognosis in cervical carcinoma. Cancer Res 55: 267-275

Packman KS, Demeure MD, Doffek KM and Wilson SD (1995) Increased plasminogen activator and type IV collagenase activity in invasive follicular thyroid carcinoma cells. Surgery 118: 1011-1017

Parker SL, Tong T, Bolden S and Wingo PA (1996) Cancer statistics. CA Cancer J Clin 65: 5-27 
Peterson G and Barnes S (1991) Genistein inhibition of the growth of human breast cancer cells: independence from estrogen receptors and the multi-drug resistance gene. Biochem. Biophys Res Commun 179: 661-667

Peterson G and Barnes S (1996) Genistein inhibits both estrogen and growth factorstimulated proliferation of human breast cancer cells. Cell Growth Differ 7: $1345-1351$

Schweigerer L, Breit S, Wenzel A, Tsunamoto K, Ludwig R and Schwab M (1990) Augmented N-MYC expression advances the malignant phenotype of human neuroblastoma cells: evidence for induction of autocrine growth factor activity. Cancer Res 50: 4411-4416

Schweigerer L, Christeleit K, Fleischmann G, Adlercreutz H, Wahala K, Hase T, Schwab M, Ludwig R and Fotsis T (1992) Identification in human urine of a natural growth inhibitor for cells derived from solid paediatric tumors. Eur J Clin Invest 22: 260-264

Severson RK, Nomura AMY, Grove J-S and Stemmerman GN (1989) A prospective study of demographics, diet, and prostate cancer among men of Japanese ancestry in Hawaii. Cancer Res 49: 1857-1860

Stearns ME and Wang M (1993) Type IV collagenase (MW, 72,000) expression in human prostate: benign and malignant tissue. Cancer Res 53: 878-883

Tsuchiya Y, Sato H, Endo Y, Okada Y, Mai M, Takuma S and Seiki M (1993) Tissue inhibitor of metalloproteinase 1 is a negative regulator of the metastatic ability of a human gastric cancer cell line, kkls, in the chick embryo. Cancer Res $\mathbf{5 3}$ : 1397-1402 